\title{
Research on the Dilemma and Countermeasures of Government Budget
}

\author{
Openness \\ Zhengwang $\mathrm{Li}^{1}$, $\mathrm{Yu} \mathrm{Xiao}^{2}$ \\ ${ }^{1,2}$ Wuhan Textile University, Wuhan, Hubei, 430000 \\ 346591653@163.com
}

KEYWORDS: Government Budget; Public; Predicament; Countermeasure

\begin{abstract}
In recent years, under the government actively promoting, the country public budget really made some achievements, but there are still many problems. This paper disclosed the existence of the government budget difficulties in our country, for the specific circumstances, put forward some suggestions for further study of the theory of theoretical researchers, policy makers and gradually improve policies.
\end{abstract}

\section{Introduction}

At this stage, the level of our government budget open far behind the developed countries and most developing countries, the disproportionate level of economic development in China. Therefore, accelerating the construction of the government budget is disclosed became a real problem to be solved urgently. Publication of Government budget problems of the government budget analysis to realize the plight of public presence, public measures to solve government budget with deep theoretical and practical significance.

\section{Problems Disclosure of Government Budget}

(A) Disclosure is incomplete budget

Budget should publicly through budgeting, implementation, review of the entire process. But China's current budget information to the public is only through fiscal revenue and expenditure budget and final accounts of digital data considered final implementation. The procedures for the preparation of the annual government budget, the budget for the review process and oversight review of the implementation of the budget, it can still belong to the "inside information." IBP's Open Budget Survey assesses whether the central government in each country surveyed provided to the public 8 key budget documents. Survey uses internationally recognized criteria to assess each country's budget transparency. The method developed by multilateral organizations, such as the International Monetary Fund (IMF), the Organization for Economic Cooperation and Development (OECD) and the International Organization of Supreme Audit Institutions (INTOSAI). 2012 Open Budget Survey to open the case of China's eight budget documents conducted a survey (survey results in Table 1 shows our government's main public reporting year, annual reports and audit reports, while the pre-budget report, Citizens Budget, so there is no mid-year review published .IBO score relatively high United States, its budget is throughout the entire process of public budget activities and all aspects of the Congress held a meeting to review the budget and the budget debate, the public can apply to attend the scene, also You can watch the live broadcast on 
relevant sites or television, but within the government budget process is generally not open to the public all relevant official documents and budget, whether it is submitted to the President or to Parliament, through the Internet, the media, publications and other channels to the public. However, the current situation of China's government budget public view, from the budget of the whole process there is a big gap open.

(B) The disclosure of general rough budget

Currently, the actual situation of the government budget is disclosed in "categories" budget, general budget, budget principled public ones, more details of specific projects and the lack of expenditure. On the revenue side, only the total number of China's annual disclosure of income taxes in each categories. While the aspects of public expenditure are very concerned about the budget information disclosure is also unsatisfactory. Although this year has made some achievements, such as the central budget information public, it has become increasingly refined. To announce the 2014 education expenditure budget information, for example, although there have been disclosed to the "entry" level subjects, but we also understand just how much money from the vague to now used for educational expenses for preschool know how much money, how much money for primary education, higher education, and for these expenditures for primary education, and how they are allocated, how much is used in the construction of teaching upstairs, with the number of teachers and other staff on salary, how much for teaching equipment on how much subsidies for students and so on, but we know nothing about these information. And only those specific budget information is really useful information. Current Social frequently exposed schools retained, taking, recklessly subsidies and other forms of abuse scandal. One important reason is that the vagueness of the budget to the official corruption space. Next look much public concern "Three" public funds, undoubtedly requires the central and local governments separately disclosed "Three" funding is a big step forward, but on the disclosure of the results, it was far short of the public's demands. Currently the vast majority of the central and local government departments open "Three" funding is a general figure, just released this year, the total pre-final accounts of the number "Three" funds, as well as budgets and final accounts for each expenditure figures, as well as Increase or decrease instructions. But for specific information about each but no excessive public spending, such as the most expensive vehicle purchase costs and operating costs, only the total number of announced no meaning. The vehicle must be public sector ownership, the annual purchase amount, the body's operating costs, and even cars and other personnel-related information. Such public budget is valid, the deputies and the public can judge whether it is reasonable that the expenditure, in order to truly be compressed "Three" funds to a reasonable level.

(C) Public budget is not enough time in the timing

Because the budget itself has a strong timeliness, and therefore the budget should be timely disclosed, otherwise it loses its public utility. However, there is disclosed in our budget limitations, there are still many problems.

To analyze the issue of timeliness of public budget time, we must first understand our budget from the preparation to the timing of the approval process.

(D) Government budget information is difficult to obtain public disclosure

At present, China's budget public way with active public and original has two kinds. Public information budget measure accessibility criteria should be: For active public information, should be very convenient way to obtain; Original of information, access to listen to the very smooth way. For the current budget of public speaking, the government mainly through the website to disclose budget information, the network is the main mode of public information inquiries. But our government open website, it is difficult to find budget public information directly on the website. 
Moreover, since each column and page-level department announced on the government website varies, each of the public to find, time-consuming.

In regard Original: one is a citizen apply for information disclosure channel is not smooth. Some government authorities will be limited to telephone application route, or limited express, e-mail, etc., for other forms of public information made public is not answered. At the same time, the presence of information disclosure when accepting excessive collection of personal information, require the applicant to provide additional proof material such phenomena, disguised improve application discloses the threshold; the other hand refused to answer the phenomenon is, or is not a legitimate reason to refuse to answer Happening. To involve a third party such as trade secrets withheld on the grounds, but not on whether the requested information is a commercial secret government strict judgment, nor to seek third party advice.

\section{Our Problems in Government Budget Openness}

(A) Institutional Building and slow

The first is the lack of a comprehensive budget information disclosure legal system for protection. Western countries more open budget based on a sound legal basis, as well regulate the government's behavior, but also to the public provides the basis for obtaining budget information. In a relatively high level of public budget UK, for example, in British history culture budget has held public information confidential manner, to 1978, "the official Information Disclosure Law" was promulgated, opened the prelude to the British budget information disclosure. Then in 1980 and 1991, they unveiled a "Data Protection Law", "the use of Local Government Information Act" and the "Official Secrets Act" for information on specific areas of the disclosure provides a legal guarantee. January 1, 2005, with the landmark "Information Disclosure Law" came into effect. It is these constantly improve the introduction of the law, the budget for the United Kingdom provides a fundamental guarantee open and transparent. However, in China, lack of public budget-related legal system construction is disclosed in these years, slow progress in the budget, the main reason for the low public information. Before the new "Budget Law", China's legal system does not have a budget to protect public the whole process, there is no detailed legal provisions to ensure the full aperture of public budgets, which resulted in the disclosure of budget information one-sided.

Followed by consideration of the budget, there are many loopholes in the NPC system. The law gives the National People's Congress for approval of the government budget interests, in this session, the NPC is the representative of the public to carry out the game with the government, is an important force on the budgetary constraints. However, at present, China's National People's Congress for consideration of the budget process and oversight of serious default, not a comprehensive set of institutional arrangements to effectively safeguard the NPC get all the budget information, nor an effective punishment mechanism to monitor people's congresses carry out duties Happening.

Finally, our budget is public participation in the main single. Publication of the main current budget mainly local governments at all levels as well as the central ministries, and approval, budget oversight bodies such as the National People's Congress at all levels, but did not disclose relevant information. From the development budget to all departments, agencies involved in approving the implementation of the budget should become the subject publicly, so as to protect the public's comprehensive and detailed budget.

(B) Officials and citizens lack a sense of responsibility

At the national system is not perfect, strengthen the ideological construction of the various stakeholders it is very important. However, in China, due to historical reasons, entrenched 
bureaucracy, as an official agency side of most publicly expressed reservations about the budget; and as the Principal of public awareness of democratic participation is also very weak, they did not establish the government's supervision of consciousness. Such an action would make the government a completely free choice of their advantageous way, that budget information hidden and not reported.

Some local governments in our country has made a very good public budgetary achievements, such as Jiaozuo City, Henan Province, Xinhe Town in Wenling, Zhejiang, Sichuan and white Miaoxiang etc., at the time most of the local government budget has not been carried out, they actively explore, actual local conditions into full play the initiative and creativity, to take various measures to promote the full and open budget. Summarize the reasons for their success, one is the strong support of local government officials. In the case of countries not in public institutional constraints of the budget, the local government officials to promote administrative efficiency, protect the interests of local people, the introduction of a number of positive policy initiative to open government budgets, but also the quality of disclosure is very high. Another important reason is the broad participation of local people, and actively explore the participatory budget. White Miaoxiang not only introduced as citizen participation in the budgeting stage, outside the system of democracy and the council and the people's congress system within the system combined. In the budget process, deputies and representatives of the public with respect to the local government as two important parties, reasonable discussion on the government budget, consultation, negotiation and modification, and jointly promote open and transparent government decision-making.

However, the above-mentioned phenomenon only individual phenomena, on the whole, our government officials, lack of public awareness is, most government officials did not establish a sense of responsibility to serve the people, and the public has no "hero" consciousness, with absolutely no government oversight awareness. In the absence of institutional constraints, government officials treat public budget on negative stand, you can conceal as much as possible to conceal.

(C) Technical building behind

One reason China has disclosed budget information for the public is the lack of correlation is difficult to obtain technical support, the current government did not establish a unified platform for all of the budget information published aggregated finishing. We want to obtain information about a government department's budget, we must go to the appropriate government websites to search. The various departments of the website is disorganized, try to hide, voluntarily disclosed little information, many of the key information required to apply for open, but also more complex application procedures, greatly increase the time cost of public access to information.

In addition, our public information budget there is an important reason for the lag is the lack of a scientific and reasonable budget roadmap disclosed, since the government budget has a strong timeliness, so the time for all aspects of public budget information have a reasonable arrangements to crucial. Otherwise, the effect of the budget public greatly weakened.

\section{REFERENCE:}

[1] Zhang Junjun, Luo Qiang. Us Federal Budget and the Preparation of the Latest Revelation [J]. Economic Research. 2012 (59).

[2] Liu Jinshi. The Chinese Government Budget Public: Evolution, Problems and Solutions. [J] Theory and The Reform, 2012 (04). 
[3] Ge Yongbo, Shen Liang. Fiscal Transparency Measure Research Question - A Framework [J]. Fiscal Studies, 2009 (12): 44-48.

[4] Li Hongxia. Let The Government Budget in The Sunshine: Budget Transparency Thinking [J]. Finance Research, 2011 (01).

[5] Alt Je, Dreyer Lassen D. The Political Budget Cycle is Where You Can Not See It:. Transparency And Fiscal Manipulation [J]. Epru Working Paper Series, 2005.

[6] Stiglitz J E. Information and the Change in The Paradigm in Economics [J]. American Economic Review, 2002: 460-501. 